\title{
A battery-operated circuit for a self-timing leaf diffusion resistance meter
}

\author{
B. Lammers and C. J. Stigter 1 \\ Department of Physics and Meteorology, Agricultural University, Wageningen, \\ the Netherlands
}

Accepted: 13 October 1978

Key words: leaf diffusion resistance, porometer, water vapour conductivity, battery power

\section{Summary}

A battery-operated circuit is described for use in self-timing leaf diffusion resistance (porometer) equipment. The circuit is based on an earlier successful design with mains power supply, but some modifications have improved the suitability for routine field use of the equipment.

\section{Introduction}

Epidermal water vapour conductivity (or its resistance to water vapour diffusion) is most successfully determined directly with diffusion porometers (Stigter, 1972, 1974, 1975; Stigter \& Visscher, 1975). In field applications a large number of measurements has to be made, as extensive sampling is essential throughout (Stigter \& Lammers, 1974; Stigter, 1974). Portability, mobility and simplicity in handling without a loss of accuracy and automation are preferable in intensive field use. Successful field experiences with equipment with circuitry using mains power supply (Stigter et al., 1973, esp. Ch. 7; Stigter \& Lammers, 1974) did bring forward requests on some modifications and improvements in view of the mentioned requirements for routine field use. We report below on such improvements and modifications, regarding mainly battery power supply and its consequences, a different digital volt meter (DVM) and its light-emitting diode (LED) displays and some details of automation and calibration of the measuring procedure. Basic features and details not discussed below (changed either kept as reported earlier by Stigter et al., 1973) can be found in a more detailed internal report (Lammers, 1978). The main features of our circuitry are collected in Fig. 1. Details of front panel items are indicated in Fig. 2 and the equipment is fully shown by Fig. 3.

1 Now at the Physics Department, University of Dar es Salaam, Tanzania. 


\section{Battery power supply}

Two batteries of ten $1.2 \mathrm{~V}$ cells each are applied. One, with a $0.1 \mathrm{~A}$ :h capacity, supplies the humidity sensor and temperature sensor measuring circuits. The other, with a $2 \mathrm{~A} \cdot \mathrm{h}$ capacity, now supplies directly the DVM and the fan motor circuit. Maximum discharge current from the latter battery is $365 \mathrm{~mA}$ (for 5-5.5 hours). The state of the battery can be checked on the DVM by a check button. Maximum discharge current from the former battery is $5.4 \mathrm{~mA}$ (much longer than 5.5 hours). The different power supply did not change the principle of the square wave oscillator (SWO) nor that of the voltage regulator (VR).

Again steatite and teflon insulation bear the circuits between SWO and CO 20 rectifier (humidity measuring circuit) and between VR and DVM (temperature measuring circuit). This time it was not necessary to rebuild the input circuit of the rectifier on better insulating material, because of the use of polyester glass fibre as print plate material. Switching (Temp/Hum) between these circuits had to be adapted to the new conditions, as rectifier and DVM had a fixed connection because of their related supplies.

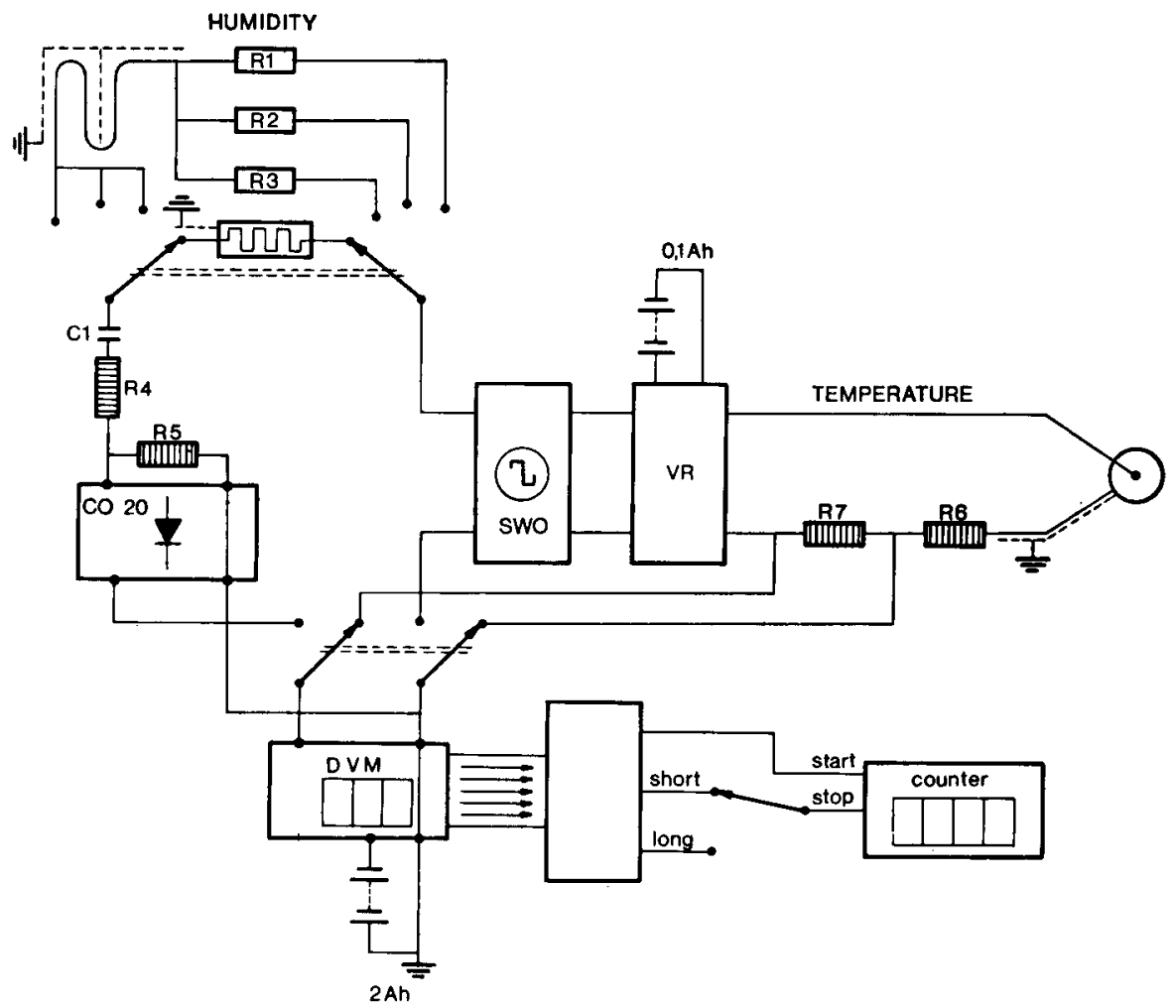

Fig. 1. Main features of the measuring circuitry for the battery-operated self-timing porometer. 
A change in the earth connection of the screen of the sensor cable led to more dominant lead capacitors. To simulate these capacitors in the dummy calibration resistance measurements, a shielded cable of equal length (ca. $2 \mathrm{~m}$ ) has now been incorporated in this circuit, instead of the capacitors $\mathrm{C} 1$ to $\mathrm{C} 3$ from the former circuit.

\section{Digital volt meter}

We use this time an again improved DVM (Schneider VT 4050). The current flowing out of the input terminals is small. We measured a temperature-independent misreading of $2 \mathrm{mV}$ over an $8 \mathrm{M} \Omega$ resistance (to be compared with the same misreading over $10 \mathrm{k} \Omega$ in the former case). Therefore the formerly applied impedance transformer could be dropped, the temperature-measuring circuit having a measuring resistance in the order of $800 \mathrm{k} \Omega$, with the $\mathrm{CO} 20$ having a DC output impedance of only $100 \mathrm{k} \Omega$. Of course parallel recording possibility is dropped at the same time but this was only included for research purposes.

Artificial heating to keep the DVM at constant temperature could be kept out. The DVM itself has now a $5 \mathrm{mV}$ stability regarding its input/output differences at temperatures varying between 20 and $40{ }^{\circ} \mathrm{C}$, but this is largely compensated by giving now a negative temperature coefficient to the VR.

\section{LED displays}

We wanted to use miniature LED displays which, combined with low-power electronics, appreciably diminish consumption of current. For this purpose we modified the DVM by replacing its display by such a miniature one. An identical display, next to the DVM one, serves as a time counter. Through a clock/count

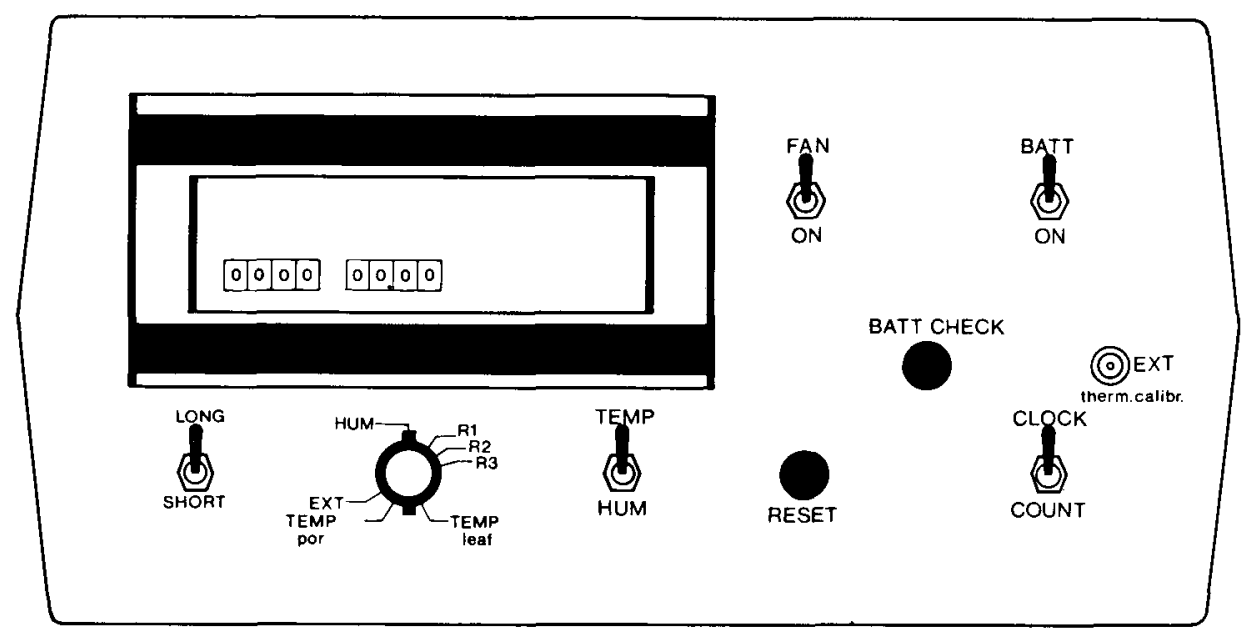

Fig. 2. Front panel lay out for porometer operation. 


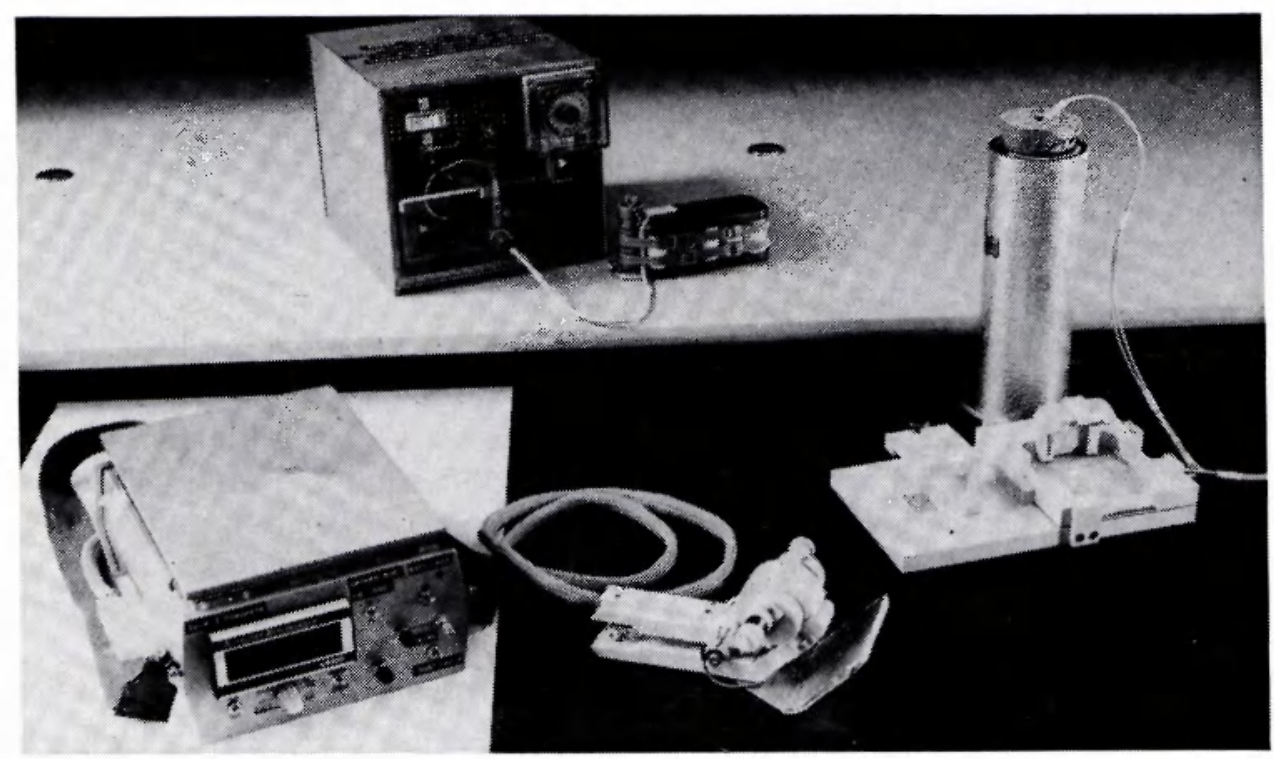

Fig. 3. Diffusion porometer connected to its electronical equipment (in front), calibration facilities (at the right) and a battery unit in front of its charging equipment.

switch it can be used alternatively for keeping track of the waiting time between two consecutive measurements and for counting the time between passes of two fixed resistance values of the sensor in use. The new displays used ca. $100 \mathrm{~mA}$ less battery current compared with the original one, which was just enough to supply the electronics outside the DVM.

\section{Automation and calibration details}

The choice of R4 and R5 determines which part(s) of which sensor range is distributed over which part(s) of the two-volt DVM range. This is a matter of choice depending on the application and the same applies to the related choices of dummy calibrated reference resistances, R1 to R3. It applies also to the choice of one fixed measuring time, two fixed measuring times (for example a short and a long one to study influences on stomatal opening as in our former case) or a choice between several ranges (two, i.e. long/short, as designed in Fig. 1 and 2, or more). Corrections on the DVM indications for the dummy sensors can be made with the SWO adjustable potentiometer, if they are out of a certain tolerated range.

Because these DVM values indicate the operability of the equipment before calibration and before measurement, only variations in these indications inbetween calibration and measurement induce errors. At temperature variations between 20 and $40^{\circ} \mathrm{C}$ and battery variations between 14 and $11 \mathrm{~V}$ we measured a maximum relative error of $3 \mathrm{mV}$ on a DVM scale length of $1000 \mathrm{mV}$. So from this we get an error of $0.3 \%$ of any measuring time. 
Instead of the $50 \mathrm{~Hz} \mathrm{AC}$ to derive the clock rate from, we now use a crystal oscillator circuit. With its frequency of $100 \mathrm{~s}^{-1}$ and a DVM sampling rate of $50 \mathrm{~s}^{-1}$, the accuracy of the time measurement between two fixed sensor resistances becomes $\pm 0.03 \mathrm{~s}$.

An external coaxial connection on the panel front side yields the opportunity for introducing calibrated resistances into the measuring circuit for thermistor indication identification purposes. Recalibration of thermistors should of course be done independently. We used this time the DVM range of $2000-4000 \mathrm{mV}$ for temperature indications $\left(5-50{ }^{\circ} \mathrm{C}\right)$ to prevent interference with the range used for the humidity sensor indications.

\section{Final remarks}

The final electronical equipment weight, housing and batteries included, is ca. $4 \mathrm{~kg}$ and its dimensions are $20 \mathrm{~cm} \times 10 \mathrm{~cm} \times 28 \mathrm{~cm}$. Incorporating the above described modifications we believe to have built very suitable and accurate porometer equipment for routine field use that is battery-operated and self-timing. More details on circuit diagrams, print designs etc. are available from our department (Lammers, 1978).

\section{Acknowledgments}

Mr T. M. Böhmer and Mr J. J. M. Polman, both of the Department of Horticulture of our University, have kindly assisted in building the electronics. They joined Mr H. E. Schouwink, of the same Department, as intermediates between the first users of the modified equipment and those responsible for design and original research. We thank our colleague, Ir J. Birnie, for a discussion on a draft of the manuscript.

\section{References}

Lammers, B., 1978. Porometer-electronica met batterijvoeding. Intern rapport, Vakgroep Natuur- en Weerkunde.

Stigter, C. J., 1972. Leaf diffusion resistance to water vapour and its direct measurement. I. Introduction and review concerning relevant factors and methods. Meded. LandbHogesch. Wageningen 72-3: 1-47.

Stigter, C. J., 1974. The epidermal resistance to diffusion of water vapour: an improved measuring method and field results in Indian corn (Zea mays). Agric. Res. Rep. 831: 1-25. Pudoc, Wageningen.

Stigter, C. J., 1975. Water vapour diffusion porometry for leaf epidermal resistance measurements in the field. In: D. A. de Vries \& N. H. Afgan (Ed.), Heat and mass transfer in the biosphere. Scripta Publ. Comp., New York, pp. 403-412.

Stigter, C. J., J. Birnie \& B. Lammers, 1973. Leaf diffusion resistance to water vapour and its direct measurement. II. Design, calibration and pertinent theory of an improved leaf diffusion resistance meter. Meded. LandbHogesch. Wageningen 73-15: 1-55.

Stigter, C. J. \& B. Lammers, 1974. Leaf diffusion resistance to water vapour and its direct measurement. III. Results regarding the improved diffusion porometer in growth rooms and fields of Indian corn (Zea mays). Meded. LandbHogesch. Wageningen 74-21: 1-76.

Stigter, C. J. \& G. J. W. Visscher, 1975. Application of a new calibration method to an unventilated dynamic diffusion porometer. Neth. J. agric. Sci. 23: 303-307. 